Objectives: To determine the frequency and associated factors of UIP among RA patients

Methods: This was a retrospective study conducted at the Rheumatology department of Farhat Hached University Hospital from 2005 to 2020. We included all RA patients who had undergone high-resolution computed tomography (HRCT) scans of the lung. Demographic data, disease characteristics, pulmonary function tests (PFT) and drugs intake were collected at the time of the realization of the HRCT. UIP pattern and NON-UIP patterns were based on HRCT results. Khi-2 and T-student tests were used in the univariate analysis. Binary logistic regression was used in the multivariate analysis. Statistical significance level was set at $5 \%$.

Results: Fifty-nine patients with RA patients having HRCT of the lung were identified among them $27.1 \%$ (16) were male. The mean age of the patients was $60.27 \pm 11.3$ years; the mean disease duration was $7.16 \pm 2.9$ years and current or previous smoking habits were recorded in $18.8 \%$ (11) of our population with a median. Secondary Sjogren's syndrome and cutaneous rheumatoid nodules were documented in $33.9 \%$ (20) and $10.17 \%$ (6) respectively. RA was erosive in $81.5 \%$ (48) of our population. The median tender joint count and the median swollen joint count were 10 and 4 respectively. The mean erythrocyte sedimentation rate (ESR) and the mean C-reactive protein (CRP) were $49 \pm 20.31 \mathrm{~mm}$ and $32 \pm 14.07 \mathrm{mg} / \mathrm{dl}$ respectively. The mean disease activity score (DAS $28 \mathrm{ESR}$ ) was $5.49 \pm 1.66$. The median rheumatoid factor and Anti-CCP levels were 260UI/ $\mathrm{ml}$ and $68 \mathrm{Ul} / \mathrm{ml}$ respectively. Exertional dyspnea (stage 2 or higher) was present in $42.37 \%$ (25) and inspiratory crackles were found in $22.4 \%$ (13) of our patients. PFT revealed a restrictive ventilatory defect, an obstructive pattern and a mixed pattern were found in $20.3 \%$ (12), 13.6 (8) and $3.4 \%$ (2) respectively. The mean DLCO value was $70 \pm 24.6 \%$. According to HRCT results, parenchymal involvement was found in $83.1 \%(49)$ of our patients and among them, we documented UIP pattern in 18 (36.73\%), Non Specific Interstitial Pneumonia (NSIP) in $14.28 \%$ (7), unclassifiable fibrosis in 14.29 (7), organizing pneumonia in $2 \%$ (1) and isolated pulmonary nodules in $32.6 \%$ (16). Pleural effusion was found in $5.1 \%$ (3) and airways disease in $15.3 \%$ (9). Mediastinal lymphadenopathy was found in $15.25 \%$ (9). Abnormalities on HRCT lead to a change in treatment in $30.5 \%$ (18) of our patients. Compared to the group with a non-UIP pattern, male sex was significantly associated with UIP pattern on HRCT $(47.4 \%$ vs. $17.5 \%$, $\mathrm{p}=0.016)$. UIP pattern was significantly associated with smoking $(37.5 \%$ vs. $9.4 \%$ $\mathrm{p}=0.022$, Unadjusted $\mathrm{OR}=5.88,95 \% \mathrm{IC}=[1.217-27.634]$ ), with cutaneous rheumatoid nodules $(31.3 \%$ vs.3.4\%, $p=0.017$, Unadjusted $\mathrm{OR}=12.72,95 \mathrm{IC}=[1.331-$ $121.658])$ and with the presence of lymphadenopathy on HRCT (41.2\% vs. $6.5 \%$, $\mathrm{p}=0.004$, Unadjusted $\mathrm{OR}=10.15,95 \% \mathrm{IC}=[1.803-57.140])$. There was no significant difference between the two groups regarding age $(p=0.454)$, disease duration $(p=0.126)$, DAS28 $(p=0.447)$, anti-CCP level $(p=0.454)$. After multivariate analysis, male sex (Adjusted $O R=11.58,95 \% I C=[1.622-82.67] p=0.015)$, Presence of lymphadenopathy on HRCT (Adjusted OR=10.53, 95\%IC $=[1.146-96.87]$, $\mathrm{p}=0.037$ ) and exertional dyspnea (Adjusted $\mathrm{OR}=6.43,95 \% \mathrm{IC}=[1.036-40.011]$, $\mathrm{p}=0.046$ ) were independently associated with UIP pattern.

Conclusion: UIP was present in $36.73 \%$ and it was the most prevalent pattern of lung involvement in RA. It was associated with male sex, mediastinal lymphadenopathy and exertional dyspnea.

Disclosure of Interests: None declared

DOI: 10.1136/annrheumdis-2021-eular.4178

\section{POS0589 PREVALENCE AND SEVERITY OF STRESS AT HOME AMONG PATIENTS WITH RHEUMATOID ARTHRITIS: SINGLE CENTRE RESULTS FROM THE PRIME REGISTRY COHORT}

M. Haroon ${ }^{1}$, F. Hashmi ${ }^{1}$, S. Ullah ${ }^{1}$, A. Ashraf ${ }^{2}$, H. J. Shaheen ${ }^{1}$, S. Asif ${ }^{1}$, S. Batool ${ }^{1}$. Fatima Memorial Hospital \& FMH College of Medicine and Dentistry, Department of Rheumatology, Lahore, Pakistan; ${ }^{2} \mathrm{CMH}$ Lahore Medical College \& Institute of Dentistry, Medicine, Lahore, Pakistan

Background: In chronic inflammatory diseases like rheumatoid arthritis (RA) psychological stress is widely recognised as an important risk factor to negatively affect the disease course. Stress activates the hypothalamic-pituitary adrenal axis and the autonomic nervous system, which associate with the release of neurotransmitters (i.e. norepinephrine), hormones (i.e. cortisol) and activation of immune cells. Perceived stress can potentially induce the disease exacerbation, but on the other hand, the disease itself might produce significant stress to patients thus the vicious circle is formed and maintained.

Objectives: We aimed to examine the prevalence of mental/emotional stress at home and its associations among patients with Rheumatoid arthritis. We addressed this question using real-world data from the PRIME registry.

Methods: This was a cross-sectional study conducted using data collected at the time of patient enrolment in the PRIME registry. The PRIME Registry is a large, independent, prospective, observational cohort initiated in October 2019 that comprises patients diagnosed with RA, SLE, PSA or AS by a rheumatologist, and is being actively followed up. IRB approval and informed consent was obtained. We assessed the data for RA patients. The clinical variables studied were gender, age, smoking habits, body mass index, education status, marital status, disease duration, comorbidities (using Charlson Comorbidity Index) Education status was stratified by whether participants completed secondary (high) school education. Evaluation of disease activity and severity was made as per internationally agreed definitions, such as: swollen joint counts, tender joint counts, deformed joint counts, and DAS-28. All participants were directly inquired at the interview during the time of patient enrolment about the presence or otherwise of mental/emotional stress at home, and to rate it from 1-3 (mild, moderate severe). For better understanding and ease of statistical analysis, dichotomous variable was made with moderate-to-severe stress patients were categorised into one group and none-to-mild stress patients into second group.

Results: The data of consecutive 507 RA patients (mean age $42.3 \pm 12.6$ years, $73.6 \%$ female, disease duration of $80 \pm 22$ months) was reviewed. Forty-eight percent of patients accepted to have moderate-severe stress at home (moderate stress $=29.9 \%$, severe stress $=18.3 \%$ ). On univariate analysis, significant association of moderate-severe stress at home was noted with deformed join counts $(p=0.036)$, higher DAS-28 scores $(p<0.001)$, and being married $(p=0.001)$ Weak statistical association of age $(p=0.11)$, disease duration $(p=0.13)$, low education status $(p=0.14)$, female gender $(p=0.24)$ was noted. On multiple logistic regression analysis, a significant association of moderate-severe stress at home was observed with higher DAS-28 scores (OR 1.76, Cl 1.29-2.41, $\mathrm{p}<0.001$ ) and deformed joint counts (OR 1.15, $\mathrm{Cl} 1.00-1.31, \mathrm{p}=0.040$ ). Following variables were included in multiple stepwise regression analysis: age, disease duration, low education status, married, Das-28 scores, and deformed joint counts. However when gender was included in the regression analysis, a significant association of moderate-severe stress at home was observed with female gender (OR 3.99, C 1.47-10.83, $\mathrm{p}=0.007$ ), higher DAS-28 scores (OR 1.8, $\mathrm{Cl} 1.31-2.51, \mathrm{p}<0.001$ ), with marginal association with deformed joint counts (OR 1.13, $\mathrm{Cl}$ 0.99-1.30, $\mathrm{p}=0.061$ ) Conclusion: Stress at home is common among patients with RA, and nearly half of the cohort was noted to have moderate-severe level of stress at home. Ongoing stress at home has significant association with higher RA disease activity and deformities suggesting a bidirectional relationship. These findings demonstrate an important need for integration of rheumatologic, social workers and mental health services

Disclosure of Interests: Muhammad Haroon Speakers bureau: Roche, Novar tis, Grant/research support from: Abbvie, Pfizer, Farzana Hashmi: None declared, Saadat Ullah: None declared, Arfa Ashraf: None declared, Hafiza Javeria Shaheen: None declared, Sadia Asif: None declared, Shabnam Batool: None declared DOI: 10.1136/annrheumdis-2021-eular.4181

\section{Rheumatoid arthritis - biological DMARDs}

\section{POS0590 SAFETY AND EFFICACY OF BIOLOGICS IN ELDERLY PATIENTS WITH RHEUMATOID ARTHRITIS IN A REAL WORLD STUDY: USE OF INTRAVENOUS GOLIMUMAB AND INFLIXIMAB IN ADULTS WITH RHEUMATOID ARTHRITIS $\geq 65$ YEARS OF AGE}

J. Schechtman ${ }^{1}$, A. Broadwell ${ }^{2}$, S. Kafka ${ }^{3}$, S. Black ${ }^{4}$, S. Xu ${ }^{5}$, W. Langholff ${ }^{5}$, S. Schwartzman ${ }^{6} .{ }^{1}$ Sun Valley Arthritis Center, Rheumatology, Peoria, United States of America; ${ }^{2}$ Rheumatology and Osteoporosis Specialists, Rheumatology, Shreveport, United States of America; ${ }^{3}$ Janssen Scientific Affairs, LLC, Immunology, Horsham, United States of America; ${ }^{4}$ Janssen Research \& Development, LLC, Immunology, Spring House, United States of America; ${ }^{5}$ Janssen Research \& Development, LLC, Biostatistics, Spring House, United States of America; ${ }^{6}$ Weill Cornell Medical College, Rheumatology, New York, United States of America

Background: AWARE is a real-world evidence-based (RWE) study evaluating the safety and efficacy of IV golimumab (GLM) and infliximab (IFX) in adults with RA.

Objectives: Evaluate safety and efficacy of IV GLM and IFX in elderly AWARE participants.

Methods: AWARE, a prospective non-interventional study (88 US sites), enrolled patients (pts) initiating either IV GLM or IFX. Pt management was at the discretion of treating rheumatologists. In a post hoc analysis, pts were grouped by age $(<65 / \geq 65 / \geq 75 \mathrm{yrs}$ ). Adverse events (AEs) were collected through the Week (W) 52 database lock (DBL; completed W52 or discontinued study) and at the end-of-study DBL (W104). The primary endpoint was proportion of pts with $\geq 1$ infusion reaction through W52. Change from baseline in Clinical Disease Activity Index (CDAI) scores at Months 6 and 12 were secondary endpoints evaluated in bionaïve pts, including those with IFX dose escalation.

Results: 1270 pts were enrolled (685 IV GLM; 585 IFX). 1047 (82\%) pts were female; mean age was $60 \mathrm{yrs}(57 \%<65 \mathrm{yrs}, 43 \% \geq 65 \mathrm{yrs}$, and $7 \% \geq 75 \mathrm{yrs})$. Mean disease durations were 9 yrs (IV GLM) and 7 yrs (IFX). Comorbidities were generally similar between IV GLM and IFX groups but more common among pts $\geq 65$ 